\title{
Memes sobre las tecnologías en las escuelas. Un estudio de las producciones estudiantiles
}

\section{Memes about technology in schools. A study of student productions}

\section{Memes sobre tecnologia nas escolas. Um estudo das produções dos estudantes}

Virginia Saez, Consejo Nacional de Investigaciones Científicas y Técnicas / Instituto de Investigaciones en Ciencias de la Educación, Universidad de Buenos Aires, Ciudad de Buenos Aires, Argentina (vsaez@filo.uba.ar)

Dafne Carp, Instituto de Investigaciones en Ciencias de la Educación, Universidad de Buenos Aires, Ciudad de Buenos Aires, Argentina (dcarp@filo.uba.ar)

RESUMEN | Los memes constituyen objetos culturales que, por su potencia y proyección, generan modos novedosos de construcción del conocimiento. Como objetivo general nos proponemos caracterizar y analizar las producciones del concurso de fotografías y memes Los Medios en las Escuelas 2019 en el contexto argentino. Los participantes, de entre 12 a 18 años, fueron motivados a expresar su reflexión sobre los medios y tecnologías en el aula mediante memes. A partir del análisis cualitativo de una muestra de 32 piezas, estos últimos se evidencian como recursos simbólicos significativos para los adolescentes, por su capacidad de condensación de sentidos identitarios, en su relación con las tecnologías y su diferenciación con los adultos.

PALABRAS CLAVE: memes; identidad; estudiantes; escuela secundaria; Argentina. 
ABSTRACT / Memes are cultural objects that, because of their power and impact, generate innovative modes of knowledge construction. As a general objective, weintend to characterize and analyze the productions of the photography and memes contest Memes in The Media in School 2019 in the Argentinian context. The participants, aged 12 to 18 years, were motivated to express their reflection on the media and technologies in the classroom through memes. From the qualitative analysis of a sample of 32 pieces, the latter are evidenced as significant symbolic resources for adolescents, due to their capacity to condense identity senses, in their relationship with technologies and their differentiation from adults.

KEYWORDS: memes; identity; students; high school; Argentina.

RESUMO | Os memes são objetos culturais que, devido ao seu poder e projeção, geram novas formas de construir o conhecimento. Como objetivo geral pretendese caracterizar e analisar produções do concurso de fotografias e memes chamado "A Mídia na Escola 2019" no contexto Argentino. Os participantes dentre 12 e 18 anos foram motivados a expressar sua opinião sobre a mídia e tecnologia na sala de aula usando memes. A partir da análise qualitativa de uma amostra de 32 peças, encontramos os memes como recursos simbólicos significativos para os adolescentes, devido à sua capacidade de condensação de sentidos de identidade, na sua relação com as tecnologias e sua diferenciação com os adultos.

PALAVRAS-CHAVE: memes; identidade; alunos; ensino fundamental; Argentina. 


\section{INTRODUCCIÓN}

Los memes de Internet producen una textualidad donde aparece quién mira y quiénes son mirados, donde se producen discursos específicos llenos de significados. Son producto de un grupo que ocupa un lugar en la estructura social, fruto de una elección que involucra valores estéticos y éticos. Constituyen herramientas útiles para los cientistas sociales, dado que son fuentes multimodales de fenómenos de comunicación, que aportan información con un valor mayor por su potencialidad semiótica y, además, son considerados formas de discurso que se generan en la red a partir de la interacción social, que tiene un amplio valor cultural, y son portadores de representaciones simbólicas (Valverde, 2015, en González-Carmona, 2017). Sirven para establecer una determinada visión del mundo en la mente del público y desarrollan un rol importante dentro de los contenidos de comunidades y espacios de pertenencia, ya que pueden ejercer efectos cognitivos y afectivos. Un meme tendrá poder e impacto por lo que muestra y por cómo lo muestra, de acuerdo con el contexto de comunicación y los fines determinados. El análisis de estas nuevas formas de comunicación permite identificar y entender algunos elementos de la configuración identitaria de quienes los crean, comparten e incluso se apropian de ellos (Vélez, 2012, en González-Carmona, 2017). Por esta razón, en esta investigación se realiza un análisis de los memes presentados en el concurso de fotografías y memes Los Medios en la Escuela 2019, en el que se incentivó a estudiantes de distintas escuelas de Argentina a producir memes reflexionando sobre el uso de los medios y las tecnologías en el aula. Este concurso se llevó a cabo con dos objetivos principales. En primer lugar, la producción de memes pone en juego distintas habilidades y manejos de las nuevas alfabetizaciones (Saez, 2019a). De acuerdo con Arango Pinto (2015), la realización de un meme implica habilidades digitales, como la selección de un tema, que puede requerir búsqueda de información, la edición y la difusión. Por otro lado, la estructura del meme requiere de un gran poder de síntesis para poder condensar lo que se quiere transmitir en una imagen, un texto breve o un video. Por último, el conocimiento de cierto registro y de algunos rasgos contextuales, como por ejemplo algunos elementos de la cultura pop, son importantes a la hora de crear memes y también de comprenderlos..

El segundo propósito del concurso fue poder explorar, entender y describir las representaciones que habitan las escuelas sobre los medios, la comunicación y la tecnología, de modo que podamos darle voz a la propia concepción de los estudiantes sobre el valor de las tecnologías de la información y de las comunicaciones (TIC). Hay quienes ven en estas una herramienta de inclusión social (Buckingham, 2009) y destacan la necesidad de integrarlas a las aulas. ¿Pero qué piensan los jóvenes sobre esto? ¿Qué visiones tienen sobre el rol que juegan las tecnologías hoy en día? 
Los memes, con sus huellas y rasgos, por su aparición reciente, componen un saber escasamente valorado. En tanto documento de cultura, pueden llegar a ser indicadores de cómo es ideada una época. La búsqueda de indicios de los cambios y el reconocimiento de las tensiones y luchas presentes constituyen aspectos valorados para estudiar la educación mediática.

En este escenario, los memes a menudo son utilizados para transmitir a los lectores aquellas ideas que difícilmente pueden ser planteadas por escrito en otros géneros. Como representaciones sígnicas, son un pequeño nudo de una gran madeja de conflictos e intereses. La inmersión en la cultura digital y la exigencia por la innovación tecnológica actual demandan indagaciones que profundicen sobre los nuevos modos semióticos y las nuevas formas de construcción de conocimiento. En este punto, el estudio multimodal de los memes puede contribuir introduciendo a los estudiantes en dominios semióticos con reglas propias, en donde tienen que aprender a significar de acuerdo con ellas.

Así, el objetivo de este artículo es caracterizar y analizar las producciones del concurso de memes Los Medios en la Escuela 2019 en el contexto argentino y, de este modo, aproximarnos a los sentidos atribuidos a estos desde la mirada estudiantil, de jóvenes de entre 12 a 18 años. Se buscaron continuidades en la serie de memes seleccionados, en el intento de advertir fuerzas en tensión cuyo resultado sería el cambio o la continuidad de una forma (de un sistema, tal vez de una visión del mundo). Los memes expresan, además de las intenciones explícitas de quienes los crearon, el sistema de esquemas de percepción de pensamiento o el sistema de valores implícitos del grupo (Bourdieu, 1979). Es decir, se trata de una manifestación que nos puede conducir hacia los esquemas de percepción de pensamientos.

\section{ENFOQUE TEÓRICO}

La primera vez que se utilizó el término meme fue por Richard Dawkins (1979) en su libro El gen egoísta, para designar a una "unidad de cultura capaz de transmitirse y sobrevivir en un determinado ecosistema social" (Ruíz Martínez, 2018, p. 997). Desde entonces, el término ha sido adoptado por el discurso popular, de acuerdo con Shiffman, para describir "la propagación de elementos como bromas, rumores, videos y sitios web de persona a persona a través de Internet” (2014, p. 2). La autora distingue tres dimensiones de los ítems culturales que las personas pueden potencialmente imitar: contenido, forma y posición. La primera, el contenido, refiere tanto a las ideas como a las ideologías transmitidas. En segundo lugar, la forma es la encarnación física del mensaje, percibida por nuestros sentidos. Por último, la posición, para representar los modos en los que los aludidos y otros productores potenciales se posicionan de acuerdo con el texto y sus códigos lingüísticos. A partir 
de estos supuestos, define los memes como "(a) un grupo de elementos digitales que comparten características comunes de contenido, forma o postura, que (b) fueron creados con conocimiento mutuo, y (c) fueron distribuidos, imitados o transformados a través de Internet por muchos usuarios" (Schifman, 2014, p. 41). Esta caracterización resulta útil para comprender aquellas producciones en las que los estudiantes reproducen ciertas unidades que ya fueron utilizadas para hacer otros memes que circulan por las redes. De estas, en el caso de las producciones de memes analizadas en este estudio, lo que se imitó principalmente fue la forma, adoptando la temática propuesta por el concurso. Aun así, no todas las imágenes seleccionadas son memes, es decir, que no todas reutilizan una estructura comunicativa para resignificarla. Por su parte, Winocour (2019) llama la atención sobre la función de apropiación identitaria que tienen los memes y cómo favorecen la inclusión y la pertenencia en distintos colectivos de jóvenes. Así también, Gabriel Pérez Salazar (2017) afirma que los memes pueden funcionar como recursos para elaborar la relación de alteridad con los otros. En consecuencia, se utilizará como herramienta metodológica para observar qué elementos constituyen a los jóvenes como un grupo.

Los memes se caracterizan por la utilización y yuxtaposición de diversos recursos digitales, semánticos y literarios (Arango Pinto, 2015). Estos se unen de forma incongruente en el mismo marco: por ejemplo, puede haber incongruencia entre la imagen y el texto que la acompaña. Esto genera un "dialogismo irritante" (Huntington, 2016, p. 85 en Ruíz Martínez, 2018, p. 1016) que busca una respuesta por parte del lector. Además, los memes recurren a la intertextualidad: el contenido suele poner en relación la idea o argumento que se pretende transmitir con un fenómeno de la cultura popular que hay que conocer para poder comprenderlo. La cultura pop ejerce por tanto de base cultural común (Ruíz Martínez, 2018). Otro rasgo propio de los memes es el humor. De acuerdo con Shifman (2009), “los textos humorísticos pueden transmitir información sobre temas sociales, a menudo ridiculizando las desviaciones de 'lo correcto' (Billig, 2005; Boskin, 1997, p. 2567). Por lo tanto, los valores y las normas pueden ayudan a determinar el éxito de una broma. El humor, de acuerdo con Argano Pinto (2015), también es usado en los memes como una forma de crítica social. Un tipo específico de meme, muy difundido hoy en día, es la estructura semiótica macro. "Esta consiste en una imagen fija, acompañada de un texto inserto en esta. En ocasiones este texto suele tener dos partes: una prótasis o proposición, en la parte superior de la imagen, y una apódosis a modo de conclusión, refutación o paradoja en la parte inferior" (Ruíz Martínez, 2018, p. 1012). Hay algunas imágenes que se usan frecuentemente para producir memes, alternando el texto en cada caso. De hecho, los principales programas o aplicaciones para generar memes consisten en un catálogo de imágenes a las que se les puede superponer de forma sencilla el texto correspondiente. La mayor parte de las producciones seleccionadas en este estudio puede inscribirse en esta categoría. 
En un escenario de convergencia tecnológica los memes emergen como una narrativa recurrente de los espacios digitales (Racioppe \& Párraga, 2020) y se han convertido en un género discursivo presente en el campo escolar, tanto que algunas investigaciones (Lara \& Mendonça, 2020) sugieren la incorporación de los memes en los libros didácticos con el propósito de actualizar las prácticas de enseñanza en la escuela.

El medio por el cual más circulan los memes, al menos en Argentina, es Instagram (Racioppe \& Párraga, 2020), por lo cual asumimos que las producciones de los estudiantes están basadas en publicaciones encontradas en esta red social. Las páginas de memes de Instagram están, en general, administradas por una o más personas de forma anónima. El tipo de meme más utilizado es la imagen macro. "Las imágenes se obtienen de bancos de Internet, de capturas de programas de televisión, de series, de películas y también de las mismas redes sociales digitales; luego se les agregan textos que anclan los sentidos" (Racioppe \& Párraga, 2020, p. 53). En consecuencia, suponemos que el predominio de memes con imágenes macro en las producciones de los estudiantes se debe a la influencia que ejercen sobre ellos estas cuentas de Instagram.

\section{Descripción del caso de estudio}

Nuestra inquietud por estudiar los modos semióticos de los memes sobre la escuela secundaria surgió en el marco del proyecto de investigación Proyecto FiloCyT FC19008 Sentidos $y$ Prácticas sobre la Educación Mediática en el nivel secundario y del proyecto de divulgación PIUBAMAS Descolonización de la mirada. Un dispositivo de acompañamiento para el uso de los medios de comunicación como herramienta pedagógica en la formación docente, que tienen por objeto explorar y comprender las prácticas mediadas por tecnologías de los jóvenes estudiantes y docentes en las escuelas argentinas.

El caso seleccionado para el estudio fue el concurso Los Medios en las Escuelas 2019, que tuvo dos propósitos. Por un lado, explorar, comprender y describir las representaciones que habitan las escuelas sobre los medios, la comunicación y la tecnología. Por otro, contribuir en los jóvenes estudiantes a desarrollar la capacidad expresiva y promover la creatividad sobre el uso de los medios en las escuelas.

Desde los proyectos que enmarcan esta publicación, el concurso convocó a la comunidad educativa a presentar memes con el objetivo que reflexionaran sobre cómo se usan los medios tecnológicos en el espacio educativo, cómo aprendemos con los medios, y qué potencialidad tienen los medios para la enseñanza en los distintos niveles educativos. Los concursantes tenían la opción de aportar observaciones aclaratorias junto con la entrega de las piezas. Se presentaron trabajos desde distintos niveles educativos, modalidades y regiones del país, conformando una muestra de 32 producciones, de jóvenes entre 12 y 18 años, de establecimientos públicos de gestión estatal y privada, de todo el país. 


\section{ESTRATEGIA METODOLÓGICA}

Como recaudo metodológico, destacamos que los memes son polisemánticos, condensan varias capas de sentido, algunas permanentes y globales, y otras efímeras, contingentes y locales. Permiten variadas lecturas y apropiaciones, dentro de cierta comunidad de pares, que puede ser globalizada o local. Por ello, en este artículo, realizaremos una tentativa de lectura que sabemos que puede tener revisiones y ampliaciones en futuros trabajos. Dadas las características del problema de investigación, el abordaje metodológico es cualitativo. Este es consistente con el interés de nuestro trabajo en acceder a una comprensión más compleja y profunda del fenómeno de estudio, que nos coloca ante la posibilidad de contribuir a sumar conocimiento interpretativo y elaborar hipótesis sustantivas (Sirvent, 2003). De ahí la necesidad de asumir un conjunto de decisiones y desplegar estrategias y técnicas metodológicas de corte cualitativo. Se han delimitado como unidades de análisis el ordenamiento global y secuencial de la información. De acuerdo con los objetivos y el abordaje de esta investigación, se utilizó un muestreo cualitativo de carácter propositivo, no probabilístico. Con este tipo de muestra no se busca generalizar los resultados, sino aportar a la comprensión profunda del problema de investigación (Hernández Sampieri, Fernández Collado, \& Baptista Lucio, 2010). La saturación teórica (Glasser \& Strauss, 1967) se realizó con base en las categorías emergentes surgidas de los análisis preliminares. Para abordar las unidades de análisis, se trabajó con un material ya disponible, lo que Wainerman y Sautú (2011) identifican como fuentes secundarias, en tanto contienen información organizada, elaborada, producto de análisis de los concursantes, jóvenes de entre 12 a 18 años. Para observar y codificar las páginas de memes, se integró un equipo interdisciplinar con estudiantes de Letras, investigadores en Ciencias de la Educación, Ciencias Políticas, Sociología y Comunicación social. Se construyeron criterios de análisis en función del grado de adecuación a la temática del concurso y las posibilidades semióticas de cada producción.

Considerando la composición, la interacción y los procesos narrativos visuales, buscamos describir los recursos de los que se valen los jóvenes para poder transmitir su mensaje. La composición da cuenta del valor informativo, la prominencia y el encuadre. La interacción permite analizar la relación de los participantes de la imagen con la audiencia, mientras que los procesos narrativos visuales arrojan información sobre cómo estos se relacionan entre sí. Es interesante, también, analizar qué comportamientos ridiculizan los estudiantes y de este modo poder comprender la relación entre ellos y la tecnología, la forma en que se constituyen como grupo, y el modo en que se relacionan con el auditorio (con las audiencias o con sus públicos o con sus usuarios de Internet). 
Para la codificación se utilizó el Atlas Ti 7 como herramienta informática, un software especialmente desarrollado para el tratamiento de datos cualitativos. Es necesario mencionar que el momento de análisis no se ubicó en una etapa específica del proceso de investigación, sino que se entrelazará en diferentes momentos a lo largo de su desarrollo (Valles, 1997); en primer lugar, desde la organización y distribución de los modos semióticos de los materiales identificando los aspectos multimodales (Kress \& van Leeuwen, 1996), así como también el ordenamiento global y secuencial de la información (van Dijk, 1983). Con el fin de realizar un análisis multimodal, nos basamos en los aportes teóricos de Kress y Van Leeuwen para estudiar las imágenes, a lo que le sumamos el análisis textual. Este método ya fue utilizado en trabajos anteriores sobre memes de modo que se "pudiera llegar a conclusiones acerca de la metafunción representacional (sobre qué versa la imagen) y la metafunción interactiva (qué tipo de relación se establece con el espectador)" (Piñeiro Otero \& Martínez Rolán, 2016, p. 22).

A medida que trabajamos con los memes, abordamos el análisis del corpus considerando que en la producción de sentido intervienen significados producidos a partir de modos semióticos verbales y no verbales. Entendemos que las potencialidades de los soportes habilitan (o deshabilitan) el uso y la combinación de diferentes códigos semióticos y de distintos patrones de organización de la información. En un último momento, se profundizó en el significado del meme mediante un estudio global de los núcleos de sentido. Resultó imprescindible el estudio del conjunto de los memes, con la intención de analizar un proceso que permita darle continuidad. En esta etapa se consideraron dos facetas de la lectura del meme: lo denotado y lo connotado. Lo primero refiere a la imagen literal (Barthes, 1971), aquello que se muestra, que es visible y explícito. Este aspecto fue relevado con el estudio del nivel morfológico y el nivel compositivo. Lo connotado refiere a la imagen simbólica (Barthes, 1971), aquello que se muestra velado, que está oculto y que se intuye. En este estudio se presenta el análisis de las cuatro piezas que obtuvieron mayor puntaje del jurado del concurso Los Medios en las Escuelas 2019.

\section{RESULTADOS: EL USO DE LA TECNOLOGÍA EN LA ESCUELA SECUNDARIA VISTA POR LOS PARTICIPANTES}

Los jóvenes estudiantes, creadores de estos memes, despliegan toda una "estrategia comunicativa" (Riego, 1990, p. 174), puesto que todo meme es una forma discursiva de mostrar el mundo. En este proceso, la censura (ya sea impuesta o escogida mediante la autocensura), la alteración o las omisiones intencionadas de una realidad son prácticas que han rodeado habitualmente el trabajo de los creadores de los memes. 
Es por ello que en esta investigación se consideró el espacio representado en el meme y el espacio excluido - lo que queda fuera de marco, fuera del espacio de representación-, pues pensamos que lo que el meme no muestra es tan importante como lo que sí se puede contemplar.

Los memes nos aportan información tanto de lo retratado como del autor que lo realiza, su criterio estético y su conocimiento sobre el tema, entre otras cosas. Es discernible en ellos la huella o la marca del autor. Desde un parámetro técnico, diremos que los trabajos finalistas se presentan en tonalidad blanco y negro y a color, y que fueron elaborados con herramientas digitales, analógicas y manuales. A continuación, se analizarán cuatro producciones, seleccionadas por su capacidad de condensación de sentidos y constitución de recursos simbólicos, lúdicos y afectivos significativos sobre los medios y las tecnologías en las escuelas.

En el meme La obsolescencia (figura 1) la estudiante representa una escena cotidiana en las escuelas secundarias argentinas, donde un profesor está escribiendo en el pizarrón mientras los estudiantes usan sus dispositivos móviles.

Este meme está constituido por dos partes. Primero, un texto que explica la imagen y debajo, la fotografía. El texto mezcla el inglés con el español, lo cual es popular entre los jóvenes, en especial para comunicarse en las redes sociales. Además, es una forma de manifestar un meme sajón: oraciones comenzadas con una temporal encabezada por when, que indican una situación desfavorable seguida de una concesión encabezada por but, indicando la reacción ante esta situación. Varios memes en Argentina reprodujeron esta formulación manteniendo el when... but, pero el resto del texto en castellano. De este modo, se da una constelación de objetos que dan sentido a ese meme. Esta combinación de dos lenguas en un mismo enunciado es conocida como code-switching (cambio de código). Lanz Vallejo, quien estudia este fenómeno en las redes, lo describe como un elemento de la construcción de la imagen. Esta se forma a partir de los valores aprobados por la sociedad y apreciados por el individuo, que responden a la necesidad que todos tenemos de sentirnos vinculados y conectados con nuestros semejantes, pero a la vez independientes de ellos y capaces de actuar con relativa libertad. Al cambiar de código, la estudiante se inscribe en un conjunto de valores compartidos por otros jóvenes usuarios de redes sociales, quienes también mezclan el inglés con el español de un modo humorístico, a la vez que se acerca a la cultura de masas. Este comportamiento contrasta con el uso de vocabulario específico, como dispositivos móviles o aprender de una manera más didáctica, que está dirigido a los evaluadores del concurso. Parecería que se logra un juego de acercamiento-alejamiento entre la cultura juvenil y la académica. El teléfono ocupa el centro de la imagen, por lo que atrae una especial atención y la estudiante está representada en un primer plano, por lo que se encuentra a 

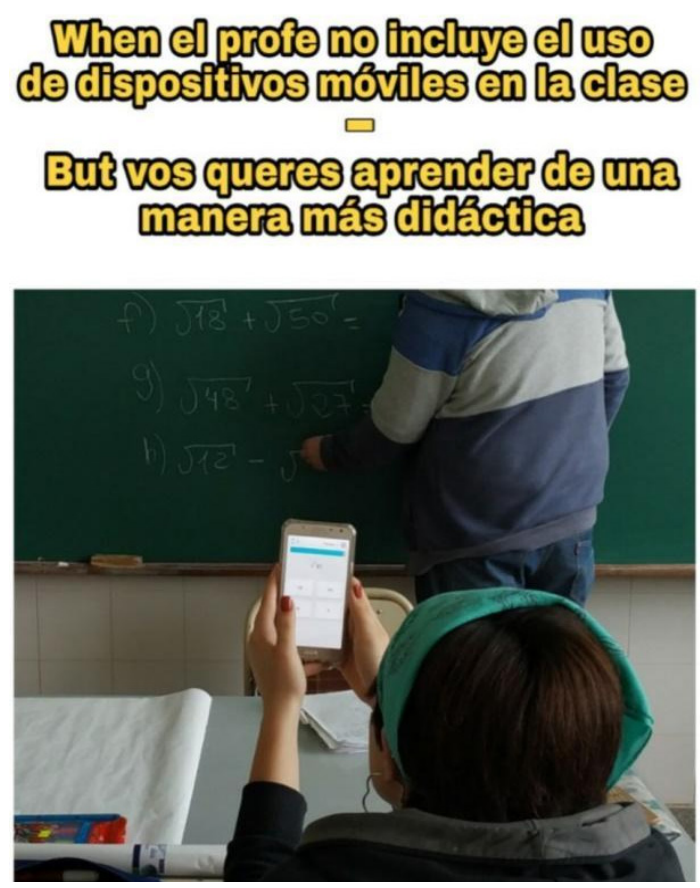

Figura 1. La obsolescencia

Fuente: Concurso de memes Los Medios en la Escuela 2019. Elaborado por estudiante femenina de 15 años, de una escuela secundaria pública de gestión estatal de San Miguel del Monte, Provincia de Buenos Aires.

una distancia social cercana. En cambio, el profesor está en el fondo y no se ve su rostro, lo cual lo hace menos prominente. En el meme parecería que se juntan dos realidades, presentadas de forma disímil e incongruente: la tecnología y la educación. La primera aparece solo en manos de la alumna, y alejada del profesor. Sin embargo, esta disyunción se resuelve en el comentario escrito que acompaña la imagen, en donde la participante observa las ventajas que tienen los métodos tradicionales y propone cómo el celular puede incorporarse a estos. El texto, además, nos permite reconstruir el proceso creador del meme, la observación de una situación recurrente en el aula: "Observamos que en las clases de las mayorías de las materias el celular es protagonista para la mayoría del curso" (Estudiante femenina de 15 años, de escuela secundaria pública de gestión estatal de San Miguel del Monte, Provincia de Buenos Aires). En las observaciones que la estudiante envió junto a su meme, aclara

Hice varias fotografías con el consentimiento de los docentes para mostrar que las formas en que las clases se dictan a veces para nosotros los millenials resultan aburridas y tediosas, considero que si los docentes hicieran uso de las herramientas tecnológicas como el celular y las muchas aplicaciones que allíse ofrecen podríamos aprender de manera más dinámica. Considero que, si bien el pizarrón y la tiza nos permiten a todos poder ver los ejercicios, en este caso de la materia matemáticas, cada estudiante tiene intereses diversos 
y observamos que en las clases de la mayoría de las materias el celular es protagonista para la gran mayoría del curso, no como uso didáctico sino como medio de escape, quizás un escape frente a algo que no nos genera interés o lo despierta. Considero que el celular forma parte de nuestras vidas, y no somos conscientes generalmente de cómo usarlo más que para entrar en redes sociales. Sería una buena manera de integrarlo y aprender si pudiéramos usarlo para aprender (Estudiante femenina de 15 años, de escuela secundaria pública de gestión estatal de San Miguel del Monte, Provincia de Buenos Aires).

La autora, en su reflexión, no descarta las ventajas que puede tener la educación tradicional. Pero advierte sobre la necesidad de integrar las nuevas tecnologías a lo ya existente. El uso de los celulares alteró las prácticas de enseñanza que se llevan a cabo en las escuelas argentinas (Lion \& Maggio, 2019; Saez, 2019a) y evidenció la necesidad de revisar la formación docente para las aulas actuales. En una investigación reciente, Iglesias (2019) muestra cómo la incorporación de los dispositivos móviles a las prácticas de enseñanza no constituye una estrategia institucional, sino que queda librada a la decisión de los profesores.

En un segundo meme (figura 2), se observa una experiencia estudiantil sobre el poder distractor de las nuevas tecnologías, especialmente de los videojuegos.

El meme combina texto e imagen. El texto introduce la narración y crea una secuencia temporal que permite comprender la imagen inferior como consecuencia de la superior. Esta estructura también es recurrente en otras manifestaciones de memes.

El efecto cómico se logra ridiculizando el comportamiento esperable del día anterior al examen. Si bien se puede optar por relajarse en las últimas horas antes de rendir, muchos estudiantes siguen repasando. El adolescente de la imagen superior (figura 2) juega tranquilamente a Fortnite, el juego más utilizado por jóvenes argentinos durante el período 2018 (Dataxis, 2020)), mientras que en la imagen inferior se ven las consecuencias de la falta de estudio. Sumado a esto, el joven no se contacta con el público en forma de demanda, por lo que se puede interpretar que el productor no busca la identificación del observador con el participante, sino que lo mire a la distancia debido al carácter reprobable de la conducta del estudiante, a pesar de que pasar tiempo con el celular es el ideal aspirado. Este meme hace evidente cierta mirada adulta sobre los usos de las tecnologías, que distingue malos usos ligados al ocio y la distracción, como los jueguitos o las redes sociales (Iglesias, 2019). Sin embargo, los videojuegos constituyen entornos inmersivos y experimentales (Oblinger, 2006; Rose, 2011). Un conjunto de investigaciones reconoce en algunos de ellos actividades que generan la necesidad de compartir la información y estimulan la fuerza de la inteligencia 


\section{Una noche antes \\ de la prueba}

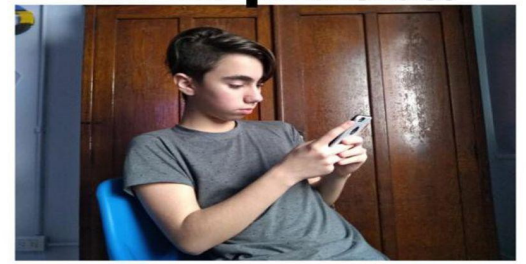

Pero en la

prueba...

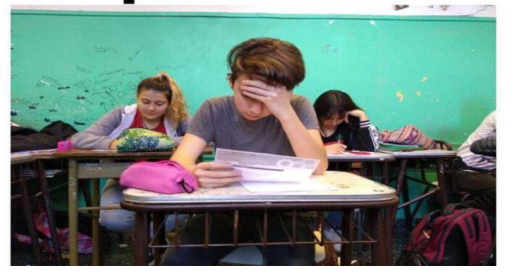

Figura 2. Fortnite

Fuente: Concurso de memes Los Medios en la Escuela 2019. Elaborado por tres estudiantes femeninas y un estudiante, todos de 14 años, de escuela secundaria pública de gestión estatal de la Ciudad Autónoma de Buenos Aires.

colectiva como fenómeno de nuestra época (Lévy, 2004). Los jóvenes jugadores son activos solucionadores de problemas que ven los errores como oportunidades para aprender y que no cesan de buscar soluciones mejores y más novedosas para los diversos obstáculos y retos (Wright, 2017). Los juegos permiten experimentar el mundo desde perspectivas alternativas. La identidad es proyectada y construida a través del juego (Gee, 2003).

Por su parte, en un tercer meme (figura 3) se representa una mirada apocalíptica sobre el uso de las tecnologías en la juventud.

Esta imagen, a diferencia del resto, no es una fotografía, sino un dibujo hecho en lápiz y tampoco constituye un meme de Internet. Surge como hipótesis interpretativa que este recurso le permite a su productora mostrar un lado negativo de la tecnología, ya que le da la posibilidad de construir una metáfora: las manos que no pertenecen a nadie dan una idea de omnipresencia y sostienen el celular y los auriculares que mantienen sujetadas a las personas del dibujo. Al utilizar lápiz negro, logra generar una atmósfera seria y depresiva que complementa el estado de ánimo de los participantes. Asimismo, el rechazo a la tecnología se ve reflejado en el medio utilizado: en vez de hacer uso de una cámara para transmitir su mensaje, la autora se abstiene de hacer una composición mediante un medio digital.

En la imagen, los participantes se encuentran en un mismo espacio a una distancia cercana, por lo cual podrían estar interconectados por una línea de 


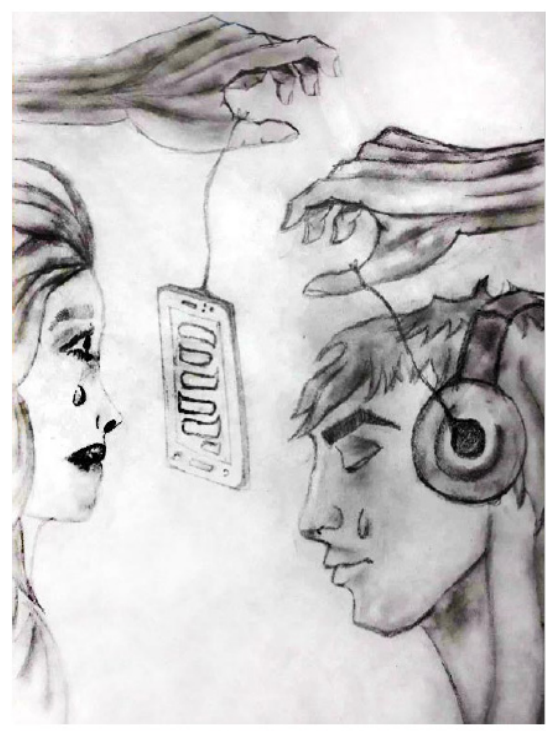

Figura 3. Desviados del camino

Fuente: Concurso de memes Los Medios en la Escuela 2019. Elaborado por una estudiante femenina de 13 años, de escuela secundaria pública de gestión privada de General Alvear, Mendoza, Argentina.

mirada pero, a causa de la tecnología, sus ojos no se encuentran. Del mismo modo, no hay ninguna mirada dirigida al observador que lo invite a involucrarse o sentirse conectado con la situación. Esto puede deberse, en parte, a que no es deseable que el público imite lo que hacen los participantes y, en parte, porque estos están tan sumidos en sus mundos dominados por la tecnología que no hacen contacto visual con los de afuera para invitarlos a formar parte de lo suyo. Para autores como Postman (1983) y Cordes y Miller (2002) los medios, especialmente los digitales, atentan y destruyen la infancia. En tanto, encuentran en los medios la causa de la agresividad y falta de interés que parecen presentar las nuevas generaciones en la escuela. Esta corriente apocalíptica $(E c 0,1968)$ tiene sus antecedentes en la Escuela de Frankfurt. Sus representantes reaccionan ante la utilización de los medios como instrumentos de control y dominación política y mercantil. Los autores acuñan el término industria cultural para referirse a toda la producción simbólica que uniformiza la cultura de masas. Sostienen que la producción mediática persigue ideologizar, homogeneizar contenidos y preferencias, fomentar gustos y necesidades y, con ello, bloquear el discernimiento de las audiencias. Los productos culturales de este tipo, pensados para ser consumidos con rapidez y de forma distraída, limitan el discernimiento mental y reproducen modelos de dominación. Bajo las lógicas del sentido práctico, los agentes interiorizan las estructuras sociales y las asumen como evidentes, configurándolos subjetivamente en sus modos de ver y hacer el mundo (Saez, 2019b). 


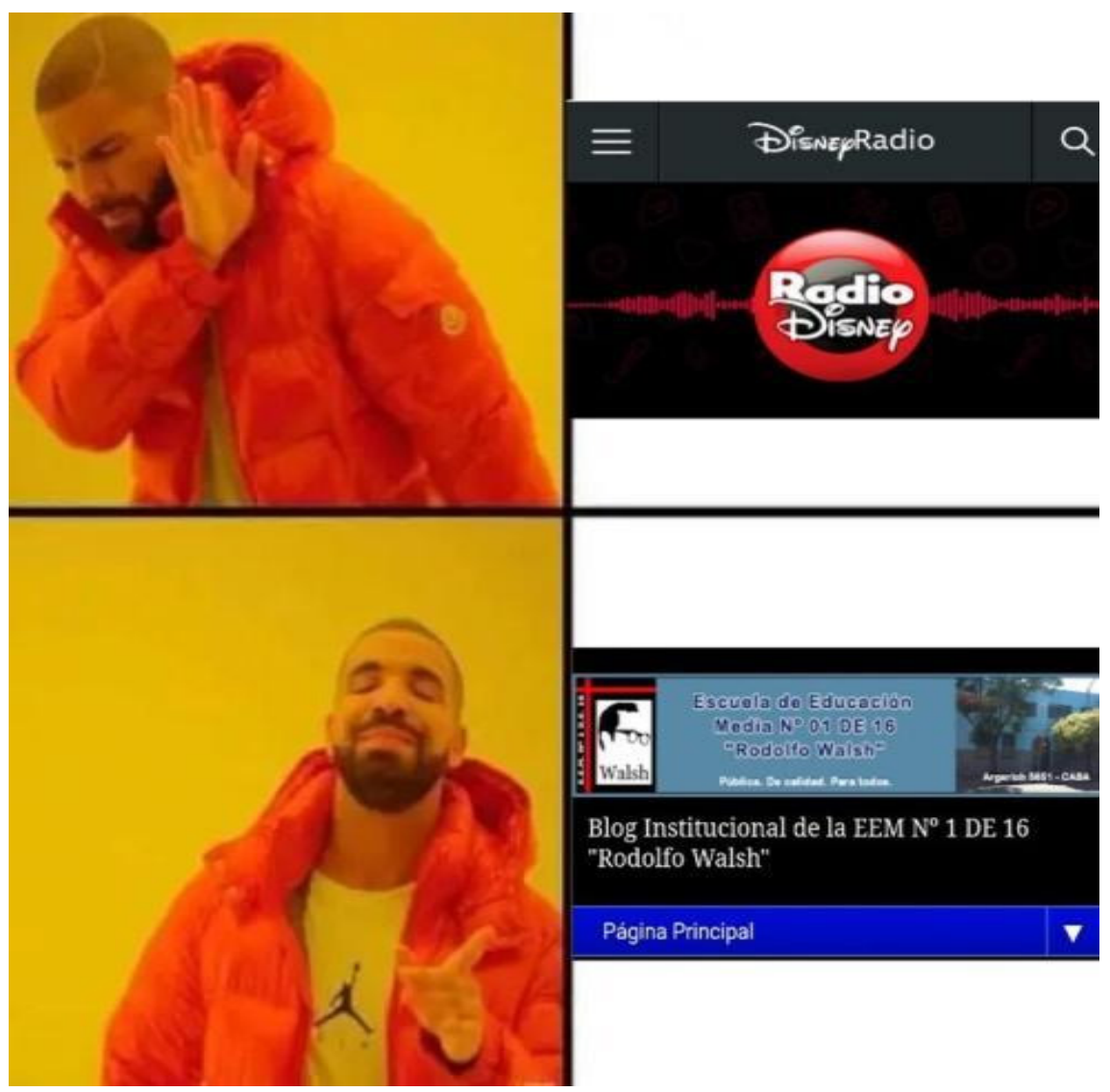

Figura 4. Bloggers

Fuente: Concurso de memes Los Medios en la Escuela 2019. Elaborado por cuatro estudiantes femeninas, de 16 años, de una escuela secundaria pública de gestión estatal de la Ciudad de Buenos Aires, Argentina.

En un cuarto meme (figura 4), se representa una identidad juvenil que las autoras llaman Bloggers.

La imagen consta de cuatro recuadros. Los dos recuadros de la izquierda muestran la conocida imagen que es utilizada en la realización de varios memes. Esta corresponde a una captura de pantalla del artista Drake tomada del videoclip de Hotline Bling, de modo que se puede observar la intertextualidad con la cultura. Un análisis de los procesos narrativos visuales de este formato de meme podría permitir identificar la relación del participante con las otras imágenes. En la imagen superior, el artista realiza un gesto de alejamiento y va siempre acompañado de algo (imagen o texto) rechazado por el productor, mientras que la imagen inferior indica lo que el productor preferiría en lugar de la imagen superior, que en este caso es el blog de la escuela Walsh. Lo humorístico se logra por la yuxtaposición incongruente de la imagen risible del artista con las imágenes que representan las preferencias de las estudiantes. Además, al emplear el rostro de alguien famoso, el meme adquiere un 
ethos vinculado a determinados valores que este representa: la cultura del rap, una mirada a la música norteamericana, pertenencia a la juventud. El blog y la radio están solamente representados por su logo, de modo que no muestran ninguna actitud de involucramiento o invitación hacia la audiencia: si bien radio Disney puede ser más conocida para los espectadores, los valores, las actividades y las temáticas que se ponen en juego dentro del blog escolar permanecen un misterio. Surge como hipótesis interpretativa que los estudiantes se reafirman como dentro del grupo escuela Walsh, dejando afuera a los observadores. Esto refuerza el sentimiento de pertenencia que generan los memes, ya que permitirían la reelaboración del mensaje desde una experiencia de apropiación identitaria. En los procesos de construcción identitaria que atraviesan los jóvenes, las escuelas secundarias se constituyen en un espacio social confiable de "identificación-diferenciación social" (Morduchowicz, 2008, p. 19) que configuran a nivel local y global las prácticas de consumo y sociabilidad.

\section{CONCLUSIONES}

En la era de la información, las tecnologías remiten no solo a nuevos dispositivos sino también a nuevos modos de percepción y de lenguaje (Barbero, 2003). La cultura de la conectividad replantea los límites de la esfera pública y privada, modifica nuestra subjetividad y las formas en las que nos comunicamos (van Dijck, 2016).

Los memes estudiados en este artículo simbolizan la mirada adolescentesobre las tecnologías en la escuela secundaria. Se identificaron distintas estrategias comunicativas y recursos multimodales con posibilidades de comunicación abierta y cifrada al mismo tiempo. Como fue posible advertir en estudios anteriores, los memes pueden ser utilizados como factor de cohesión y pertenencia identitaria, y al mismo tiempo comportarse como elementos de exclusión (Winocur, 2019).

Asumen una identidad que se define fuertemente en la creación de una alteridad. Los otros son fundamentales a la hora de fundar y consolidar el nosotros, es decir, son parte constitutiva. En la construcción de la identidad estudiantil parecería vislumbrarse la configuración de un nosotros vinculado con el uso de las tecnologías, los videojuegos (especialmente el Fortnite), el code-switching y la cultura pop. Por otro lado, aparece la conformación de un ellos adulto, atravesados por una brecha digital, donde se revelan tensiones y antagonismos entre las expectativas adultas y las vivencias juveniles. En línea con otras investigaciones, observamos que en los memes analizados se producen juegos de representaciones (Winocur, 2019) que excluyen a quienes no conocen o no comparten los códigos identitarios (Costa, Pérez Tornero, \& Tropea, 1996). 
Aun así, pareciera que tampoco se deja al adulto afuera completamente. Si bien hay una fuerte intertextualidad con manifestaciones de la cultura de masas juvenil, situaciones como la noche anterior a un examen o el aburrimiento en clase son ampliamente reconocibles. En línea con el trabajo de Lara y Mendonça (2020), este artículo identifica la necesidad de incorporar los memes como material didáctico que potencie las prácticas educativas y evidencia las miradas estudiantiles sobre la inclusión de los medios digitales en las escuelas. Las opiniones de los jóvenes sobre las tecnologías distan de ser unánimes. Por el contrario, los memes combinan miradas reivindicadoras y apocalípticas. En el meme La obsolescencia pareciera que hay una valoración positiva de la tecnología para ser aplicada de forma educativa, invita al auditor a acoplarse con el cambio en la enseñanza propuesto por la joven estudiante e incluso se hace al observador partícipe, mediante el ángulo over the shoulder por el cual este parece formar parte de la clase. En el meme Bloggers, el blog del colegio es mostrado de una manera favorable, pero el hecho de que solo tenga presencia mediante su logo no da lugar a que el observador se involucre. El blog es presentado como el lugar de pertenencia de los jóvenes estudiantes, pero no hay una propuesta más amplia con respecto al uso de las tecnologías, como en el caso de La obsolescencia, donde se busca incluir al receptor en los nuevos usos de los dispositivos electrónicos. Por otra parte, hay otras producciones en las que la tecnología pareciera ser valorada negativamente, como en Fortnite y Desviados del camino. En estas, los participantes no adoptan actitudes de demanda. Surge como hipótesis interpretativa que esto podría obedecer, por un lado, a que no quieren incentivar los usos de los aparatos electrónicos que muestran y, por otro lado, a que su uso los mantiene aislados. Esta mirada corre el riesgo de asumir a las juventudes como un grupo en riesgo por la exposición a las nuevas tecnologías, en lugar de tomarlo como un sujeto de derecho (Saez, 2017).

En suma, diversos discursos acerca de las tecnologías atraviesan las producciones de los estudiantes. Por más que se los considere nativos digitales no todos los jóvenes parecen celebrar las tecnologías, y son conscientes de su lado negativo. Por otro lado, las producciones que defienden un uso educativo de las TIC (como La obsolescencia y Bloggers) ven en estas un potencial mayor más allá del mero entretenimiento.

Para cerrar, nos gustaría hacer una reflexión sobre la experiencia de trabajo con memes de los jóvenes. Retomando la propuesta de Arango Pinto (2015), pudimos comprobar las diversas habilidades que los estudiantes tuvieron que poner en juego a la hora de su producción. En casos como La obsolescencia o Fortnite se evidenció un trabajo importante de edición, al utilizar imágenes originales a las que luego se le agregó el texto. Bloggers, en cambio, utilizó una imagen prediseñada de un generador de memes y Desviados del camino no usó siquiera la tecnología digital. Las consideraciones en torno al uso de los medios y las nuevas tecnologías de la 
información son variadas, por lo cual los estudiantes debieron analizar las distintas posiciones considerando los conocimientos contextuales sobre el tema y tomar una postura desde la cual realizar el meme. Una vez clara su opinión, la creación del meme requirió poder sintetizarla adaptándose a la gramática propia de este tipo de producción cultural. Por último, la decisión sobre la actitud o stance (Shifman, 2014) del meme repercute en su función comunicativa. Mientras La obsolescencia o Desviados del camino tienen un tono más serio, con una finalidad de denuncia, Bloggers y Fortnite optan por una actitud humorística.

Nos inscribimos, entonces, en la misma línea que otros autores (Gagliardi, 2020; Pellicer, 2016; Medina, 2018; Bernal Torres \& Vega Niño, 2019) que encontraron el trabajo con memes en el aula como beneficioso, debido a las posibilidades comunicativas que permite. Estos, que hicieron actividades con memes en las materias de prácticas del lenguaje o de matemática, reconocen el potencial de este recurso para atraer la atención de los estudiantes. Entre sus ventajas, mencionan la capacidad de trabajar con "los conocimientos que los estudiantes ya tienen sobre ellos sin recaer en aplicacionismos categoriales en la práctica docente" (Gagliardi, 2020, p. 31), de ayudar a recordar reglas, de evaluar informalmente (los que comprenden el humor del meme, comprenden el contenido), de motivar a los estudiantes en situaciones de examen (Pellicer, 2016), de fortalecer la lectura crítica (Bernal Torres \& Vega Niño, 2019), de proporcionar un elemento de análisis para trabajar habilidades lingüísticas, y de acercar la educación y la tecnología (Medina, 2018).

\section{REFERENCIAS}

Arango Pinto, L. G. (2015). Una aproximación al fenómeno de los memes en Internet: claves para su comprensión y su posible integración pedagógica (An approach to the phenomenon of Internet memes: keys for their comprehension and possible pedagogical integration). Revista CMC, Comunicação mídia e consumo, 12 (33), 110-132. Retrieved from http://revistacmc.espm.br/index.php/revistacmc/article/view/677

Barbero, J. M. (2003). La educación desde la comunicación (Education from communication). Bogotá, Colombia: Norma.

Barthes, R. (1971). Elementos de Semiología (Elements of Semiology). Madrid, España: Alberto Corazón Editor.

Bernal Torres, Y. T. \& Vega Niño, J. A. (2019). Estrategia didáctica mediada por memes para el fortalecimiento de la lectura crítica (Didactics strategy mediated by memes to strengthen critical reading). Boletín Repide, 9(10), 62-74. https://doi.org/10.36260/rbr.v9i10.1088

Bourdieu, P. (1979). La fotografía, un arte intermedio (Photography: A middle-Brow Art). Mexico City, Mexico: Nueva imagen.

Buckingham, D. (2019). Teaching media in a 'post-truth' age: fake news, media bias and the challenge far media/digital literacy education. Cultura y Educación, 31(2), 213-231. https://doi.org/10.1080/11356405.2019.1603814 
Cordes, C. \& Miller, E. (Eds.). (2002). Fool'sgold: A critical look at computers and childhood. Retrieved from http://www.eric.ed.gov/PDFS/ED445803.pdf

Costa, P. O., Pérez Tornero, J. M. \& Tropea, F. (1996). Tribus urbanas. Barcelona, España: Paidós.

Dataxis (2020). YouTube (Argentina) Monthly active users. Retrieved from https//dataxis.com/2020/youtube-argentina-monthly-active-users/

Dawkins, R. (1979). El gen egoísta (The Selfish Gene). Barcelona, Spain: Labor.

Eco U. (1968). Apocalípticos e integrados. Editorial Tusquets.

Gagliardi, L. (2020). Memes en la clase de lengua y literatura: qué, para qué y cómo (Memes in the language and literature class. What for and how). Convergencias. Revista de Educación, 3(5), 25-49.Retrievedfromhttp://revistas.uncu.edu.ar/ojs3/index.php/convergencias/article/view/3199

Gee, J. P. (2003). What video games have to teach us about learning and literacy. New York, NY: Palgrave Macmillan.

Glasser, B. \& Strauss, A. (1967). The Discovery of Grounded Theory. Strategies for Qualitative Research. Chicago, IL: Aldine.

González-Carmona, F. L. (2017). Uso De Memes Como Mediadores De Las Vivencias De Estudiantes Universitarios. In Consejo Mexicano de Investigación Educativa (Ed.), Memoria Electrónica del Congreso Nacional deInvestigaciónEducativa, SanLuis dePotosí(pp.1-11). Mexico City, Mexico:COMIE. Retrieved from http://www.comie.org.mx/congreso/memoriaelectronica/v14/doc/0594.pdf

Hernández Sampieri, R., Fernández Collado, C., \& Baptista Lucio, P. (2010). Metodología de la investigación (5aed) (Investigation methodology, 5th ed). Mexico City, Mexico: McGraw-Hill.

Iglesias, A. (2019). Celulares en las aulas. Los desafíos de los profesores de las escuelas secundarias del siglo XXI (Mobile phones in classrooms. The Challenges of Secondary School Teachers of the 21st Century). In V. Saez (Coord.), Educación de la Mirada. Experiencias, reflexiones $y$ desafíos pedagógicos de la formación en Medios, Comunicación y Tecnologías en Argentina (Gaze Education. Experiences, reflections, and pedagogical challenges of training in Media, Communication, and Technologies in Argentina). Buenos Aires, Argentina: UBA.

Kress, G. \& Van Leeuwen, T. (1996). Leyendo imágenes. La gramática del diseño visual (Reading Images: The Grammar of Visual Design). London, United Kingdom: Routledge.

Lara, M. T. A. \& Mendonça, M. C. (2020). O meme em material didático: considerações sobre ensino/aprendizagem de gêneros do discurso (Memesin TeachingMaterial: Considerations on theTeaching and Learning of Speech Genres). Bakhtiniana: Revista de Estudos do Discurso, 15(2), 185-209. https://doi.org/10.1590/2176-457342169

Lanz, L. (2011). El cambio de código español-inglés como creatividad lingüística y presentación de la imagen en tweets escritos por tijuanenses (The change of the Spanish-English code as linguistic creativity and presentation of the image in tweets written by Tijuana residents). In Memorias de las Primeras Jornadas de Lenguas en Contacto (Proceedings of the First Conference on Languages in Contact) (pp. 64-73). Tepic, Mexico: UAN.

Lévy, P. (2004). Inteligencia colectiva: por una antropología del ciberespacio (Collective Intelligence: Mankind's Emerging World in Cyberspace). Washington, D.C.: Organización Panamericana de la Salud. 
Lion, C. \& Maggio, M. (2019). Desafíos para la enseñanza universitaria en los escenarios digitales contemporáneos. Aportes desde la investigación (Challenges for university education in contemporary digital scenarios. Contributions from the research). Cuadernos de Investigación Educativa, 10(1), 13-25. https://doi.org/10.18861/cied.2019.10.1.2878

Medina, F. (2018). Los memes como discurso analizable en el aula (Memes as analysable discourse in the classroom). Cuaderno de Pedagogía Universitaria, 15(30), 12-21. https://doi.org/10.29197/cpu.v15i30.307

Morduchowicz, R. (2008). Introducción (Introduction) . In R. Morduchowicz (Coord.), Los jóvenes $y$ las pantallas. Nuevas formas de sociabilidad (Young people and screens. New forms of sociability) (pp. 9-24). Barcelona, Spain: Gedisa.

Oblinger, D. (2006). Simulations, Games, and Learning. Boston, MS: Harvard Press.

Pérez Salazar, G. (2017). El meme en Internet, identidad y usos sociales (The meme on the Internet, identity and social uses). Coahuila, Mexico: Fontamara.

Piñeiro-Otero, T. \& Martínez-Rolán, X. (2016). Los memes en el activismo feminista en la red. \#Viajo sola como ejemplo de movilización transnacional (Memes in the Internet feminist activism. \#ViajoSola as an example of transnational mobilization). Cuadernos.info, (39), 17-37. https://doi.org/10.7764/cdi.39.1040

Pellicer, P. B. (2016). Utilizando memes con tus alumnos (Using memes with your students). Números. Revista de Didáctica de las Matemáticas, 91,129-134. Retrieved from https://zaguan.unizar.es/record/57751/files/texto_completo.pdf

Postman, N. (1983). The disappearance of childhood. London: W. H. Allen.

Racioppe, B. \& Párraga, J. (2020). Memes en Instagram: un estudio de caso de cuentas dedicadas a la producción y circulación de estas narrativas contemporáneas (Memes On Instagram: A Case Study Of Accounts Dedicated To The Production And Circulation Of These Contemporary Narratives). Perspectivas de la Comunicación, 13(1), 47-84. https://doi.org/10.4067/S0718-48672020000100047

Riego, B. (1990). La fotografía como fuente de la Historia Contemporánea: las dificultades de la evidencia (Photography as a source of Contemporary History: the difficulties of the evidence). In La imatge i la recerca històrica: Ponències $i$ comunicacions : Jornades de debat entorn del valor artístic $i$ documental del patrimoni en imatge (The image and historical research: Papers and communications: Conference on the artistic and documentary value of heritage in image) (pp. 167-180). Girona, Spain: Ayuntament di Girona.

Rose, F. (2011). The Art of Immersion: How the Digital Generation is Remaking Hollywood, Madison Avenue, and the Way We Tell Stories. New York, NY: W. W. Norton \& Company.

Ruíz Martínez, J. M. (2018). Una aproximación retórica a los memes de Internet (A rethorical approach to Internet memes). Signa: Revista de la Asociación Española de Semiótica, (27), 995-1021. https://doi.org/10.5944/signa.vol27.2018.21856

Saez, V. (2017). El Derecho a ser Joven desde la Prensa Argentina (The Right to be Young in the Argentinian Press).Educação \& Realidade,42(4),1421-1438. https://doi.org/10.1590/2175-623662360

Saez, V. (2019a). La Educación Mediática en la Escuela Secundaria desde los diseños curriculares (The Media Education in Secondary School from the curricular designs). Entramado, 15(2), 148-159. https://doi.org/10.18041/1900-3803/entramado.2.5629 
Saez, V. (2019b). Los rasgos de la educación mediática en el nivel secundario: un estudio del caso argentino (Characteristics of media literacy education at the secondary level: An Argentinian case study). Actualidades Pedagógicas, (74), 1-17. https://doi.org/10.19052/ap.vol1.iss74.5

Shifman, L. (2007). Humor in the Age of Digital Reproduction: Continuity and Change in Internet-Based Comic Texts. International Journal of Communication, 1(1), 187-209. Retrieved from https://ijoc.org/index.php/ijoc/article/view/11

Shifman, L. (2014). Memes in digital culture. Cambridge, MS: MIT Essential Knowledge Series.

Sirvent M. T. (2003). El Proceso de Investigación. Investigación y Estadística I (The Investigation Process. Research and Statistics I). Buenos Aires, Argentina: Oficina de Publicaciones de la Facultad de Filosofía y Letras (Opfyl).

Valles, M. S. (1997). Técnicas cualitativas de investigación social: reflexión metodológica y práctica profesional (Qualitative techniques of social research: methodological reflection and professional practice). Madrid, Spain: Síntesis.

Van Dijck, J. (2016). La cultura de la conectividad. Una historia crítica delas redes sociales (The Culture of Connectivity: A Critical History of Social Media). Buenos Aires, Argentina: Siglo XXI.

Wainerman, C. \& Sautú. R. (2011). La trastienda de la investigación científica (The Backroom of Scientific Research). Buenos Aires, Argentina: Manantial.

Winocur, R. (2019). La tribu de los memes. Un territorio virtual de inclusión-exclusión entre los adolescentes (The tribe of memes. A virtual territory of inclusion-exclusion among adolescents). Comunicación y Sociedad, 1-22. https://doi.org/10.32870/cys.v2019i0.7327

Wright, M. T. (2017). Paradox of the learning game. Philadelphia, PA: Design Meets Mind.

\section{FINANCIAMIENTO}

Esta investigación fue posible gracias al financiamiento de los proyectos "Sentidos y Prácticas sobre la Educación Mediática en el nivel secundario" (FiloCyT-FC19008 2019/2021) de la Facultad de filosofía y letras de la Universidad de Buenos Aires, Argentina y "Descolonización de la mirada. Un dispositivo de acompañamiento para el uso de los medios de comunicación como herramienta pedagógica en la formación docente" (PIUBAMAS2020-6-2020/2021) de la Universidad de Buenos Aires. La investigadora principal es, en ambos casos, Virginia Saez. 


\section{SOBRE LAS AUTORAS}

DAFNE CARP, estudiante avanzada de Letras con orientación en lingüística en la Universidad de Buenos Aires y adscripta en Lingüística. Becaria UBACyT del proyecto Nuevos modos de construcción de conocimiento en la era digital. Un estudio sobre los modos semióticos de los videojuegos Fortnite y Clash Royale. Investigadora estudiante del proyecto UBACyT La construcción de conocimiento sobre los medios de comunicación en la formación docente. Un estudio sobre sus sentidos y prácticas (Directora: Virginia Saez).

(iD https://orcid.org/0000-0003-4234-8606

VIRGINIA SAEZ, doctora en Educación por la Universidad de Buenos Aires (UBA) y posdoctorado en Comunicación, Medios y Cultura. Su actividad docente se desarrolla en la UBA y se desempeña como investigadora asistente en el Consejo Nacional de Investigaciones Científicas y Tecnológicas, con sede en el Instituto de Investigación en Ciencias de la Educación de la de la UBA. Realiza actividades de investigación, docencia y extensión en el estudio de las relaciones entre los medios de comunicación y la escuela.

iD http://orcid.org/0000-0002-3043-4614 